\title{
Ensinado Programação apoiada por um ambiente virtual e exercícios associados a cotidiano dos alunos: compartilhando alternativas e lições aprendidas
}

\author{
Lucia Maria Martins Giraffa, Luana Muller, Márcia Cristina Moraes \\ Faculdade de Informática - PUCRS \\ Avenida Ipiranga 6681-predio 30 - Porto Alegre -RS 90610-900 Brasil \\ \{giraffa@pucrs.br,luana.muller@pucrs.br,marcia.moraes@pucrs.br\}
}

\begin{abstract}
This paper presents the lessons learned from a methodology created to support the teaching programming for beginners based on a virtual classroom and exercises linked with student leisure interests. We also discuss the challenges and possibilities arose from integration of multiple spaces and existing tools on the Internet.
\end{abstract}

\section{Resumo}

Este artigo apresenta os resultados e as lições aprendidas relacionadas a uma metodologia para apoiar o ensino de programação para iniciantes. Buscou-se criar alternativas para ampliar o espaço de encontros presenciais com a criação de uma sala de aula virtual e uso de enunciados de exercícios que nos permitissem aproximar dos interesses dos alunos por meio de situações ancoradas nos seus hábitos de lazer. Discute-se a questão dos desafios e possibilidades da integração de múltiplos espaços e ferramentas existentes na Internet, a questão da motivação para realizar as tarefas a partir da oferta de exercícios que estejam relacionados ao cotidiano dos alunos.

\section{Palavras-chave}

Ensino de Programação. Salas Virtuais. Metodologias.

\section{Entendendo o contexto, o problema e a metodologia.}

A preocupação com a evasão escolar é um problema que afeta todos os níveis de escolarização e os cursos na área de Computação não fogem a esta regra. Programas da UNESCO ${ }^{1}$ buscam incentivar docentes e instituições a buscarem alternativas para mitigar a desistência e suas consequências, as quais impactam não somente as instituições de ensino, bem como a sociedade como um todo. Dentre as múltiplas diretivas incentivadas pelo relatório destaca-se uma que motiva a escrita deste registro: socializar e difundir experiências e ações relacionadas a metodologias que auxiliem a premência do aluno e consequente continuidade do seu estudo.

A relevância e atualidade do tema abordado neste artigo podem ser mensuradas pelo fato dos estudos investigativos relacionados ao ensino de programação não serem recentes e há tempos preocuparem os docentes da área de Computação justamente por não haver uma solução definitiva para o problema. A preocupação com o tema agravou-

\footnotetext{
${ }^{1}$ http://www.unesco.org/new/pt/brasilia/education/
} 
se nos últimos anos em face da baixa procura das carreiras envolvendo engenharia e programação. A Sociedade Brasileira de Computação (SBC) ${ }^{2}$, as sociedades americanas $\mathrm{ACM}^{3}$, $\mathrm{IEEE}^{4}$ e diferentes entidades europeias ${ }^{5}$ publicam relatórios e boletins em seus sites alertando para o problema e deflagrando uma ampla reflexão na comunidade docente e discente. Eventos da área de Computação tais como Technical Symposium on Computer Science Education, SIGCSE ${ }^{6}$, European Counterpart, Innovation and Technology in Computer Science Education (ITiCSE) ${ }^{7}$ são fóruns interessantes para buscar elementos e experiências relacionados ao desafio de ensinar programação e a questão da baixa procura pelas carreiras de Engenharia e Computação. ACM e IEEE também publicaram recomendações relacionadas aos currículos e ensino na área de Computação ${ }^{8}$ buscando garantir padrões de qualidade e indicando alternativas para captação de novos alunos e fixação dos mesmos nas carreiras.

Os fatores que levam os jovens a optarem por outras carreiras não serão discutidos neste artigo. O foco é discutir e apresentar uma proposta de ensino que motive o aluno a aprender e auxilie o discente a persistir na carreira escolhida. Acredita-se que além das questões relacionadas às competências e habilidades prévias que o aluno deve possuir para estudar Computação, uma parcela significativa da evasão pode ser controlada pela atuação docente.

A forma com que o espaço presencial e virtual se organiza influi na maneira com que os alunos se relacionam entre si e com seus professores. Um ambiente que incentive a leitura, a troca de experiências e o diálogo pode auxiliar o aluno a manter-se no curso. $\mathrm{O}$ uso de espaços virtuais pode auxiliar a interação do grupo e permitir a criação de uma comunidade virtual de aprendizagem.

O ensino de programação é associado ao ensino de Algoritmos. Ou seja, para aprender a programar o aluno deve aprender a pensar algoritmicamente, uma vez que a organização lógica e estrutural do programa devem ser possíveis de serem executadas pelo computador. O computador possui uma estrutura interna muito simples se comparada a nossa estrutura de pensamento. Nós humanos temos a capacidade de processar informações incompletas, confusas, redundantes, mal organizadas e mesmo assim conseguimos resolver problemas mal formulados. Nossa impressionante capacidade de estabelecer associações e interligações nos permite criar alternativas de soluções aos mais diversos problemas. Mas para programar é necessária uma abordagem mental diferente e o entendimento de como funciona esta ferramenta: o computador. As operações são básicas e simples se comparadas as nossas. E, a organização física e lógica deste recurso são baseadas em construtores relacionados à Matemática.

Existem diferentes paradigmas para se programar computadores. Assim como as demais áreas do conhecimento, o ensino de programação evoluiu em função dos avanços tecnológicos e das necessidades da sociedade. Durante muitas décadas o ensino de programação para iniciantes foi realizado usando o paradigma da programação estruturada com linguagens de programação como Pascal e C. Por esta razão a grande

\footnotetext{
2 http://www.sbc.org.br/

3 http://www.acm.org/

4 http://www.ieee.org/index.html

${ }^{5}$ http://www.informatik.uni-trier.de/ ley/organizations.html

${ }^{6} \mathrm{http}: / / \mathrm{www}$. sigcse.org/sigcse2012/

7 http://www.cs.kent.ac.uk/events/iticse2001/

${ }^{8} \mathrm{http} / / / \mathrm{www} . \mathrm{acm}$. org/education/curricula-recommendations
} 


\section{CBIE-LACLO 2015}

Anais dos Workshops do IV Congresso Brasileiro de Informática na Educação (CBIE 2015)

maioria dos estudos envolvendo o ensino de programação usa como base este paradigma. A primeira autora deste artigo leciona Algoritmos e Programação para iniciantes desde 1987 onde vivenciou as dificuldades e as limitações encontradas pelos alunos ao chegarem à universidade. Nestes mais de 20 anos atuando no ensino de programação é visível o impacto da perda de qualidade da formação básica que os alunos estão recebendo no Brasil. Evidente que o lócus de nossa pesquisa e observação é a cidade de Porto Alegre, Rio Grande do Sul. Entretanto, as politicas e orientações curriculares no Brasil recebem forte influencia do governo central (federal). E a crise na formação de professores, a baixa procura pelas carreiras docentes, especialmente na área de Matemática e Física, geram reflexos na formação dos alunos e impactos negativos na universidade. Nos anos de 2012 a 2014 conduzimos pesquisas para identificar as causas do abandono e desistência nas disciplinas de $1^{\circ}$ nível nos cursos de programação (Giraffa, Moraes, 2012; Giraffa, Mora 2013) e encontramos que, apesar das deficiências relacionadas aos pré-requisitos de Matemática, os alunos apontam que os fatores principais são: o não entendimento dos enunciados, exercícios dissociados de problemas "reais" e pouca disponibilidade extraclasse para estudos são obstáculos para sua aprendizagem. A questão não pode ser colocada de forma reducionista uma vez que são muitos os fatores intervenientes para que o abandono e a evasão da disciplina ocorram. No entanto, a pesquisa mostrou um cenário um tanto diferente daquele costumeiramente apontado em pesquisas na literatura.

O trabalho desenvolvido pelos ingleses Bennedsen e Caspersen (2007) foi o usado como impulsionador da investigação que originou a proposta metodológica aqui relatada. O trabalho dos autores apresenta o resultado de uma pesquisa realizada no ano de 2007 que objetivava avaliar indicadores que poderiam ser "padrões" nas instituições de todo o mundo relacionados às taxas de evasão em cursos de introdução à programação. $\mathrm{O}$ artigo descreve o encaminhamento da pesquisa e seus resultados. $\mathrm{O}$ número de instituições que responderam ao instrumento (questionário) foram 67 universidades dos cinco continentes. Os autores esperavam um número expressivo de instituições respondentes do instrumento e ficaram bastante frustradas com o retorno. Mas até este retorno foi objeto de reflexão e influenciou os autores a tecerem conclusões menos firmes e generalizadoras, mas não menos importantes para os docentes da área de Computação. Esta pesquisa deu início a toda uma trajetória investigativa destes autores relacionada ao ensino de programação para iniciantes onde foram investigados os aspectos relacionados às habilidades e competências necessárias para se aprender a programar orientado a Objetos ${ }^{9}$. Quando se buscou confrontar estes estudos com similares no Brasil (Delgado et al, 2005; Raabe, 2005; Raabe, 2006; Raabe, 2007) observaram-se indicadores semelhantes . Ou seja, a falta de competências e habilidades relacionadas a conteúdos de Matemática, limitações no uso da memória para relembrar o que já foi aprendido, capacidade de ler enunciados e entendê-los de forma clara e analítica são fatores que levam os alunos a não conseguirem entender os conceitos basilares da programação.

Tendo estes elementos identificados na literatura e que combinavam com a observação e informações relacionadas à nossa prática organizamos uma proposta/abordagem metodológica para trabalhar com os alunos de maneira a envolvê-los mais no processo e permitir que trabalhassem de forma mais participativa na construção do seu conhecimento. A proposta metodológica sugerida pelas autoras foi avaliada na forma de

\footnotetext{
${ }^{9}$ Publicações relacionadas a este estudo: http://www.daimi.au.dk/ mec/publications/index.html
} 


\section{CBIE-LACLO 2015}

Anais dos Workshops do IV Congresso Brasileiro de Informática na Educação (CBIE 2015)

um estudo de caso baseado nos resultados de 3 turmas da disciplina de Fundamentos e Programação I na realidade da Faculdade de Informática da PUCRS (Brasil). Utilizaram-se como instrumentos de registro notas de aula, observações acerca do comportamento dos alunos, depoimentos espontâneos, depoimentos induzidos em perguntas no fórum após a entrega das notas finais e analise dos resultados das avaliações das 3 turmas comparadas aos dados histórico da disciplina nos últimos 6 anos.

Existem diferentes formas do professor abordar o processo de ensino e o de aprendizagem em relação aos seus alunos. Segundo Becker (2001), essas formas podem ser sintetizadas em três pedagogias fundamentais: centrada no professor, a qual tende a valorizar relações hierárquicas e a anular a capacidade criativa do aluno, bastando que este repita o que já lhe é apresentado "pronto"; centrada no aluno, a qual em geral acaba por atribuir ao aluno qualidades que este não tem, como domínio do conhecimento sistematizado e domínio de didáticas; e centrada na relação aluno-professor, a qual tende a desabsolutizar a hegemonia prévia de ambas as partes, pois estas trazem suas "bagagens" e constroem o conhecimento em conjunto. Cada uma destas pedagogias pode ser colocada em prática através de metodologias de ensino específicas. A pedagogia centrada na relação aluno-professor pode adotar a metodologia dialética, que pressupõe ser o aluno um ser ativo no processo de aprendizagem e o professor o problematizador de situações e articulador do processo de conhecimento (Portal, 2003). Neste contexto, o professor não é mais apenas o organizador do processo de aprendizagem, este é o mediador das ações dos alunos. Assim, o professor deve provocar e propiciar as atividades do aluno; permitindo ao mesmo realizar a ação de análise e reflexão crítica. $\mathrm{O}$ aluno, por sua vez, deixa de ser um mero assistente e tornarse um agente de busca, seleção e construção do seu conhecimento, tornando-se corresponsável pelo seu aprendizado.

\section{Estruturação da Sala Virtual de apoio}

O esquema das aulas utilizadas nestas turmas de Fundamentos se baseia em um conjunto de materiais disponibilizados de maneira prévia para os alunos, através da sala Moodle $^{10}$ da disciplina. Utilizou-se a experiência com salas de aula virtual para estender as atividades das salas de aula presencial. Existem atividades mediadas presencialmente pelo professor (aula no mesmo espaço físico) e outras atividades nas quais o professor interage com os alunos de forma síncrona ou assíncrona. Este espaço virtual que consideramos como extensão da sala de aula presencial é o elemento basilar da relação com os alunos. O espaço de interação virtual (SAV - Sala de Aula Virtual) aliado a uma escolha de exercícios (desafiadores e associados a problemas que os alunos vão enfrentar como programadores) fez a diferença nos resultados das turmas.

Os recursos utilizados na SAV para suporte às atividades não presenciais baseiam-se nos seguintes serviços:

- Fórum de Avisos: espaço usado pelo professor para fazer a comunicação com os alunos. Ele substitui a lista de e-mails tradicionalmente usada para divulgar noticias e avisos aos alunos. Pode ser usado para divulgar eventos, oportunidades de cursos, leituras e outras informações relevantes;

\footnotetext{
${ }^{10} \mathrm{O}$ ambiente pode ser outro qualquer desde que possua as mesmas funcionalidades disponíveis ao professor.
} 
- Fórum das Descobertas: espaço usado pelos alunos para compartilharem suas descobertas e promover a interação entre eles;

- Cronograma das Atividades: a FACIN possui um sistema de reservas que fornece suporte aos professores e coordenação de recursos computacionais que permite distribuir as aulas praticas que correm nos laboratórios. Desta forma o professor pode disponibilizar seu planejamento e ir alterando conforme o ritmo das aulas e os naturais ajustes que soa feitos no cronograma em função da realidade da sua sala de aula. Este cronograma pode ser exportado em padrão HTML e é colocado na sala de aula virtual na forma de uma pagina ou arquivo.

- Tópicos contendo os Arquivos em formato PDF, contendo os materiais relacionados aos tópicos a serem abordados os materiais da disciplina.

- Materiais complementares em formatos multimídia. Usamos pequenos filmes gerados com uso de ferramenta de captura onde se gravava os exercícios realizados no ambiente de programação, onde a solução era comentada passo-a-passo. Foram criadas videoaulas e disponibilizadas no YouTube com explicações detalhadas do uso de recurso técnicos tais como: configuração das variáveis de ambientes para ensinar a criação de executáveis, tratamento de arquivos, usa de ferramentas extras ao ambiente de programação;

- Fórum dos monitores: espaço especial para os alunos conversarem com a monitoria;

- Mensagens: utilizadas para esclarecimento de dúvidas e comunicação privada do professor com seus alunos e vice-versa;

- Podcasts (arquivos de áudio em formato mp3: usados para complementar o trabalho desenvolvido nos encontros presencias e fornecer feedback/orientação aos alunos. Maiores detalhes do uso destes recursos foram relatadas em (Giraffa e Faria, 2012);

- Sala de entrega de Tarefas: usadas para envio de trabalhos relacionados ao sistema de avaliação;

A metodologia utilizada na condução da disciplina baseia-se na resolução de problemas organizados em ordem crescente de complexidade. Toda a questão da leitura referente à teoria e seu aprofundamento dos conteúdos fica por conta do aluno. Quando da adoção de algum livro, a sequência de leitura para este recurso é disponibilizada. A agenda disponibilizada na página permite ao aluno conhecer o cronograma da disciplina.

Cada aula inicia com um resumo dos principais pontos indicados para leitura e depois são desenvolvidas atividades práticas relacionadas com a lista de exercícios disponibilizada na página ou entregue durante a aula. A capacidade de resolver um problema e expressar a solução via um algoritmo, vai requerer que o aluno saiba analisar o problema que recebeu e seja capaz de situá-lo dentro de um contexto onde existem diversas classes de problema. Depois disto, o aluno deve ser capaz de perceber os componentes que constituem aquele problema, ter bem claro qual a solução esperada, identificar os dados disponíveis para serem computados e, finalmente, organizar uma estratégia de solução baseada nos seus pré-requisitos. Podendo, também, complementar os dados iniciais fornecidos pelo enunciado, caso seja necessário. Esta etapa de préanálise do problema pode ser feita de forma mais informal, motivando o aluno a explorar de forma mais livre o enunciado do problema, fazer conjecturas a respeito de sua interpretação, verificar se os colegas possuem a mesma percepção do problema e outras. Logo, é importante que se crie hábitos de leitura crítica dos enunciados. Isto é, os alunos invistam tempo em atividade extraclasse para realizarem leitura criteriosa do enunciado que receberam. Para tal, o professor deve conduzir esta atividade lendo o 


\section{CBIE-LACLO 2015}

Anais dos Workshops do IV Congresso Brasileiro de Informática na Educação (CBIE 2015)

enunciado ou solicitando a um dos alunos que o façam de forma sistemática sublinhando verbos que detonam as ações esperadas e sugere-se que separem as informações tendo por base o esquema $\mathbf{E}$ (entrada) $\rightarrow \mathbf{P}$ (processamento) $\rightarrow \mathbf{S}$ (saída).

Evita-se a resolução dos exercícios por parte do professor e busca-se uma postura menos diretiva por parte do docente. O problema será resolvido utilizando as contribuições dos alunos. Neste caso, o professor funciona como elemento mediador que coloca as informações no quadro (ou em dicas nos fóruns da sala virtual) e as disponibiliza para todos os alunos. Ou seja, o professor funciona como facilitador e não um guia que apresenta uma solução passo-a-passo. $O$ professor deve incentivar os alunos a colocarem suas soluções (corretas ou não) para serem compartilhadas com os colegas nos fóruns criados para discutir os tópicos em estudo. Desta forma, a turma pode constatar que não existe um modelo único de solução. Cada pessoa é um ser único no sentido de processar as informações. Cada um pode perceber os problemas de forma diferente. Logo, cada um elabora soluções diferentes. E, todas estas soluções podem estar atendendo ao problema. O que vai ocorrer é que algumas são mais otimizadas do que outras. Não se pode exigir que em uma fase inicial de construção de conhecimento, o aluno, além de conseguir elaborar o algoritmo, desenvolva-o de forma otimizada. A etapa de otimizar (melhorar o algoritmo já elaborado) é subsequente ao processo de elaboração da primeira versão. Esta etapa é muito mais complexa e difícil para o aluno iniciante.

A fim de reforçar o processo de construção de diferentes soluções para um mesmo problema, disponibilizam-se na página da disciplina (link devidamente etiquetado) vários exemplos de soluções construídas por outros alunos (até de turmas anteriores) e monitores. A monitoria desempenha um papel importante neste contexto. Os alunos têm a oportunidade de conversar sobre suas dúvidas com outro colega mais experiente. Em muitas situações, outro colega com faixa etária mais próxima e mesmo curso (ou curso de mesma área do conhecimento) consegue promover a mediação melhor que o professor. A atividade da monitoria é supervisionada pelo professor. Eventualmente, delega-se ao monitor a organização das discussões que ocorrem na lista e no fórum. Esta prática aproxima o monitor da realidade da disciplina, fazendo-o sentir-se parte da turma. Neste caso usamos a estratégia da monitoria virtual. Ou seja, foi criado um fórum especial para que os alunos se comunicassem com os monitores extraclasse em horários variados. Cabe salientar que alguns dos monitores fizeram uso do Skype para orientar os alunos, situação esta que ficou interessante. Obtivemos permissão especial para realizar este tipo de atividade uma vez que a cultura da universidade com relação à monitoria é a presencialidade. Monitores ficam fixos no laboratório em horários previamente agendados. Observou-se que, na prática, isto não funciona devido a restrições de horários em ambas as partes. A opção da monitoria virtual foi muito bem aceita. Os monitores também foram estimulados a serem autores e muitas das videoaulas disponibilizadas no YouTube foram feitas por eles.

Além de incentivar os alunos a realizaram uma leitura crítica dos enunciados propostos nos exercícios, estimula-se que realizem a leitura prévia dos materiais de aula e da leitura recomendada. Essa prática tem como objetivo contribuir para a realização de uma efetiva aula dialogada, onde os alunos participam, questionando o professor e interagindo ao serem questionados. Em relação às avaliações realizadas, busca-se que o aluno demonstre o estágio em que se encontra no processo de aquisição e construção do 
CBIE-LACLO 2015

Anais dos Workshops do IV Congresso Brasileiro de Informática na Educação (CBIE 2015)

conhecimento. Desta maneira, a avaliação consiste da realização de três provas presenciais, trabalhos práticos realizados ao longo do semestre.

\section{Os exercícios diferenciados}

Além da organização do espaço virtual que funcionou como ponto de apoio interlocução para os docentes, discentes e monitoria, um fator significativo para contribuir para motivação para estudar foram os exercícios diferenciados onde enunciados buscaram trazer experiências relacionadas ao cotidiano e lazer como mote para criar enunciados.

Optamos por usar a série Game of Thrones (GoT), o filme Vingadores, série de filmes Guerra nas Estelas e hábitos de consumo hora em moda (pulseiras configuráveis com berloques) como elementos para criar exercícios que trouxessem algum tipo de identificação com seus hábitos de lazer ou consumo. A Figura 1 apresenta um recorte do enunciado que criamos para trabalhar testes e estrutura de repetição onde foi utilizado como mote o sistema de pulseira configuráveis .

\section{Exercícios de Reforço (testes e estruturas de repeticão)}

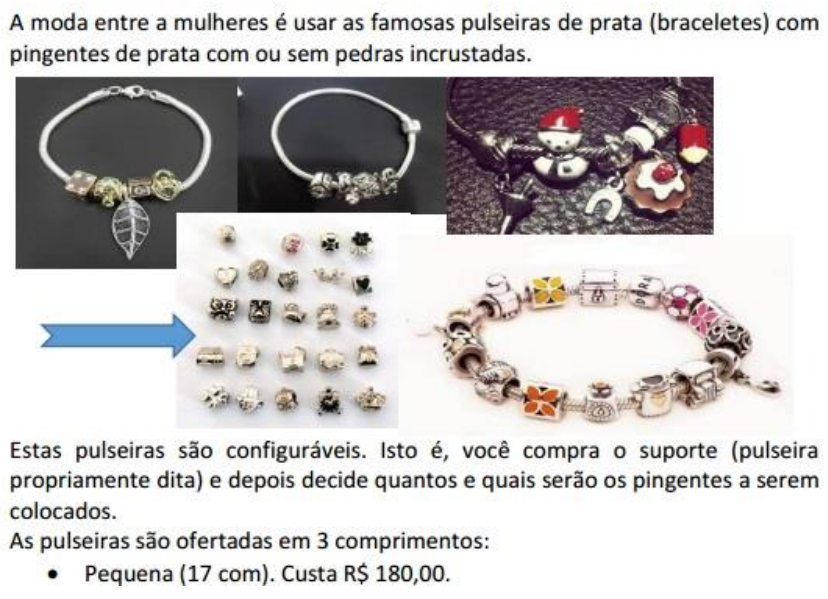

Figura 1: Enunciado para teste estruturas de seleção

O exemplo da serie GoT foi bem interessante, pois a cada semana após um episodio era disponibilizado um enunciado que fazia com que fatos do episódio corrente fossem transformados em exercícios. Exemplo disto pode ser visto na figura 2 onde fizemos uma colagem de alguns dos exercícios propostos e a forma como foram disponibilizados no ambiente virtual:
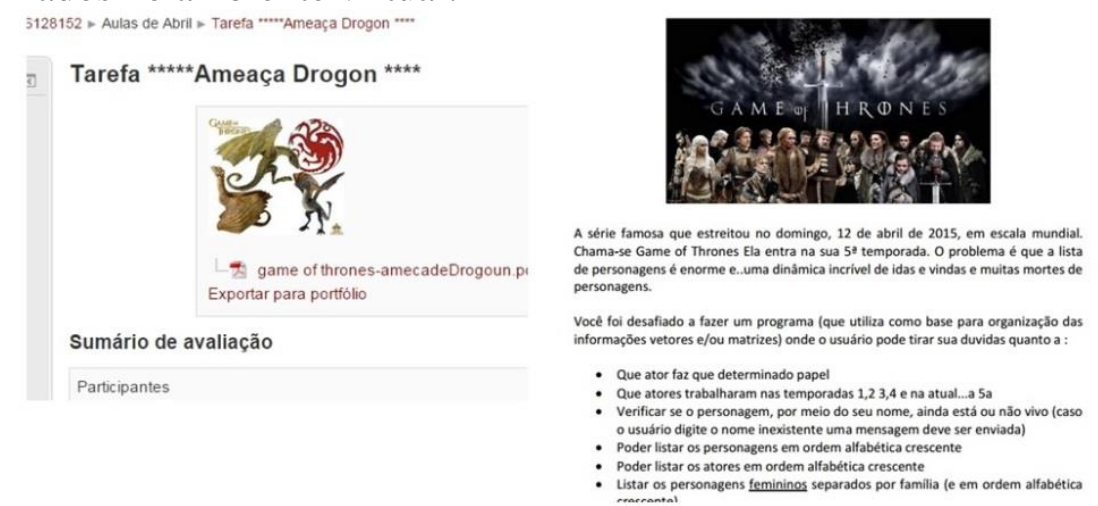
CBIE-LACLO 2015

Anais dos Workshops do IV Congresso Brasileiro de Informática na Educação (CBIE 2015)

\section{Figura 2: Alguns enunciados relacionados a serie GoT}

O filme Vingadores também foi utilizado para criação de um enunciado como mostra a Figura3.

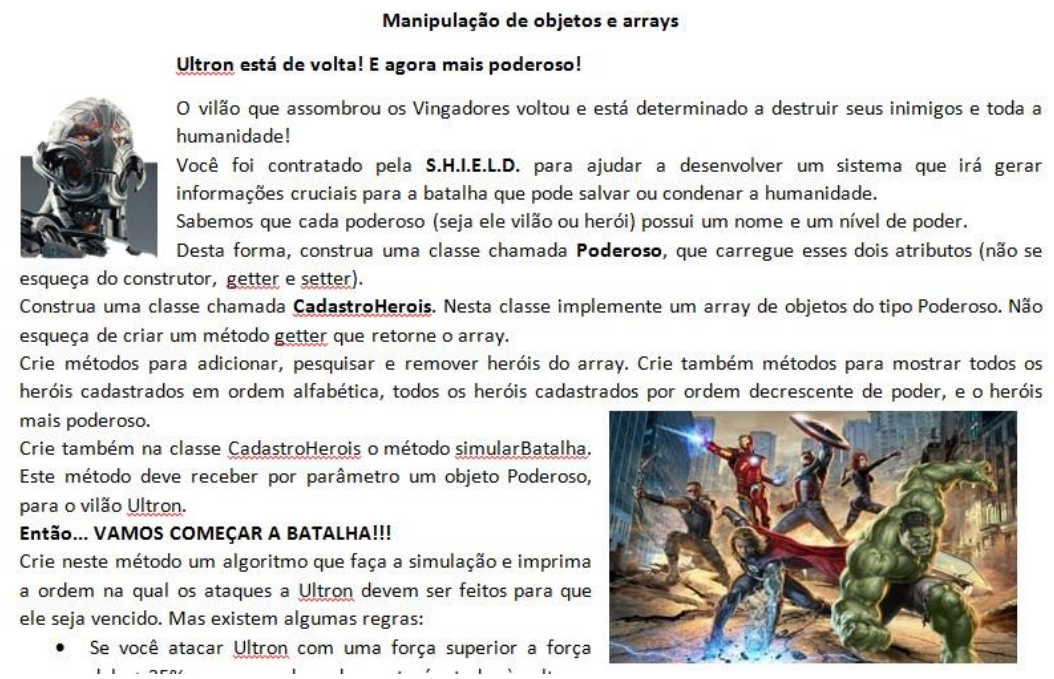

Figura 3: Enunciado relacionados ao filme Vingadores

Cabe salientar que esta abordagem foi mantida nas questões da prova onde se buscou trazer o caráter lúdico aos enunciados. Os enunciados baseados em atividades e lazer trouxeram uma contribuição extra no que tange ao esforço para abstrair os elementos fundamentais para realização do exercício. Além de sair tradicional contexto de exercícios utilizados na literatura, os quais também os utilizamos.

\section{Considerações Finais}

Esta experiência com uso destes espaços virtuais como elementos de extensão e mediação das atividades da sala de aula presencial resultou em vários pontos positivos na condução da disciplina e no aproveitamento dos alunos. O mais significativo em termos de indicador foi o comportamento dos alunos com relação aos exercícios e o trabalho de acompanhamento. Destacamos alguns pontos mencionados pelos alunos:

- A forma como o professor conduziu a disciplina incentivando-os a ler, pensar e realizar exercícios;

- O tipo de exercícios e atividades disponibilizados no ambiente e respectivos feedbacks;

- A organização do espaço virtual que lhes permitiu compartilhar com colegas soluções e dúvidas comuns;

- Um sistema de avaliação compatível com os trabalhos realizados em aula;

- O comportamento do professor com relação aos alunos: respeitoso e incentivador.

Evidentemente, uma proposta metodológica deve ser refinada a cada semestre no que tange aos aspectos operacionais (relativos ao uso dos recursos de apoio), distribuição das informações sobre a disciplina e outros. Os pontos onde geralmente são feitas as maiores alterações são: 
- Apresentação de um cronograma geral de atividades para todo o semestre. Para o aluno ter ideia do volume de trabalho (leituras, exercícios, pesquisas, tarefas práticas, etc.) a ser realizado;

- Disponibilização dos materiais de forma antecipada (no mínimo uma aula à frente);

- Adequação da tecnologia associada aos recursos para encontros síncronos e assíncronos. Algumas delas podem se mostrar inadequadas ou obsoletas. Outras podem ter problemas com os provedores privados utilizados pelos alunos fora da universidade, como no caso dos vídeos;

Pode-se ressaltar como aspectos positivos desta metodologia o envolvimento dos alunos nas atividades de aula presencial e sua participação dos alunos enviando materiais e soluções para serem compartilhadas com os colegas. Em contrapartida, pode-se considerar como aspecto negativo da mesma o enorme volume de informações que o professor e o aluno têm de gerenciar, pode-se citar como exemplo a grande quantidade postagens no fórum e documentos que o professor precisa verificar semanalmente. A escolha dos exercícios e atividades deve ser diversificada e com enunciados que permitam a aplicação direta de um conceito e sim que permita o estabelecimento relações com o aprendido e a bagagem que carrega aluno consigo, considerando suas limitações e expectativas .

Cada vez mais os alunos chegam à universidade com deficiências na sua formação. Deficiências estas relacionadas à expressão em língua materna (escrita), interpretação de textos e enunciados, hábitos de estudo e pesquisa e, especialmente, com formação deficitária no que tange a conteúdos de Matemática. Não adianta apenas o professor constar isto e dizer que os alunos já vieram assim. O fato é que depois de passarem nos exames seletivos eles agora são universitários e passam a ser responsabilidade da universidade e, por consequência, do seu professor. Cabe aos docentes e gestores buscarem soluções para transpor estas lacunas no aprendizado pregresso destes alunos.

Auxiliá-los a se motivarem para transpor estas limitações e lacunas é uma tarefa importante a ser desempenada pelo professor. Atualmente o uso da Internet e seus recursos são cada vez mais difundidos e faz parte do cotidiano dos jovens. Competir com as redes sociais e os jogos online são outros desafios do docente no século XXI que somente poderá ser superado com outro entendimento do que é ser professor neste novo contexto hipermidiatico e com pouca profundidade discussões (Giraffa e Marczak, 2012).

\section{Referências}

Becker, F. Educação e construção do conhecimento. Porto Alegre: Artmed, 2001.

Bennedsen, J.B. and Caspersen, M.E.: "Failure Rates in Introductory Programming", SIGCSE Bulletin inroads, Volume 39, Number 2, June 2007, pp. 3236.

Bennedsen, J. and Caspersen, M.E.: "Recalling Programming Competence", Proceedings of the 9th International Conference on Computing Education Research, Koli Calling 2009, Koli, Finland, October 2009, pp. 86-95. 


\section{CBIE-LACLO 2015}

Anais dos Workshops do IV Congresso Brasileiro de Informática na Educação (CBIE 2015)

Delgado, C.; Xexeo, J. A. M.; Souza, I. F.; Rapkiewicz, C. E; Pereira Júnior, J. C. Identificando competências associadas ao aprendizado de leitura e construção de algoritmos. In: XXV Congresso da SBC - X WEI (Workshop de Educação em Informática), 2005, São Leopoldo - RS. Anais do XXV Congresso da SBC, 2005. V. 1.

Giraffa, L. M. M.; Faria, E. T. . Using Podcasts To Better Qualify The Teaching Evaluation Process In Virtual Classes. In: INTED2012 (6th International Technology, Education and Development Conference), 2012, Valencia (Spain). INTED2012 (6th International Technology, Education and Development Conference). Valencia (Spain): IATED, 2012. v. 1. p. 2372-2379.

Giraffa, L. M. M.; Marczak, S. S. Being a digital teacher: myths, dilemma and challenges for $21 \mathrm{st}$ century teachers. In: EDULEARN12, The 4th annual International Conference on Education and New Learning Technologies, 2012, Barcelona (Spain). EDULEARN12, the 4th annual International Conference on Education and New Learning Technologies. Barcelona (Spain): International Association of Technology, Education and Development (IATED), 2012. v. 1. p. 112.

Giraffa, L. M. M.; Marczak, S. S. Being a digital teacher: myths, dilemma and challenges for $21 \mathrm{st}$ century teachers. In: EDULEARN12, The 4th annual International Conference on Education and New Learning Technologies, 2012, Barcelona (Spain). EDULEARN12, the 4th annual Association of Technology, Education and Development (IATED), 2012. v. 1. p. 1-12.

Raabe, A. L. A; Ilva,J. Um ambiente para atendimento as dificuldades de aprendizagem de algoritmos. In: XIII Workshop de Educação em Computação - SBC2005, 2005, São Leopoldo. Anais do XXV Congresso da Sociedade Brasileira de Computação, 2005. p. 2326-2335.

Raabe, A. L. A; Giraffa, L. M. M. Uma Arquitetura de Tutor para Promover Experiências de Aprendizagem Mediadas. In: XVII Simpósio Brasileiro de Informática na Educação - SBIE2006, 2006, Brasília - DF. Anais do XVII Simpósio Brasileiro de Informática na Educação, 2006. v. 1. p. 589-598.

Raabe, A. L. A; Dazzi, R.L.S.; Santiago, R. Adquirindo experiência na construção de ferramentas de apoio a aprendizagem de algoritmos. In: Workshop de Ambientes de Apoio a Aprendizagem de Algoritmos e Programação - Simpósio Brasileiro de Informática na Educação, 2007, São Paulo. Anais do XVIII Simpósio Brasileiro de Informática na Educação, 2007.

Portal, L. L. F. . Até que ponto a informática é um ferramenta para intervenção educativa?. In: Armando Luiz Bortolini; Valdemarina Bidone de Azevedo e Souza. (Org.). Mediação Tecnológica: construindo e inovando. Mediação Tecnológica: construindo e inovando. 1ed.Porto Alegre: EDIPUCRS, 2003, v. 1, p. 125-136. 